\title{
Effects of cashew gum and nanoparticles on cooled stallion semen
}

\author{
Kahynna Cavalcante Loureiro 1,2,3, Isabel Bezerra Lima-Verde ${ }^{4 *}$, Anders Johannisson ${ }^{4}$, Theodoros Ntallaris ${ }^{4}$, \\ Alessandro Jager ${ }^{3}$, Petr Štěpánek ${ }^{3}$, Marcelo da Costa Mendonça ${ }^{1,2}$, Patrícia Severino ${ }^{1,2}$ and Jane M. Morrell ${ }^{4}$ (D)
}

\begin{abstract}
Background: Cryopreservation of stallion spermatozoa tends to cause plasma membrane damage due to the low ratio of cholesterol to phospholipids. Gums have been suggested as an alternative cryoprotectant to glycerol for stalIion spermatozoa. Therefore, the present experiment was designed to verify whether the effect of addition of cashew gum (CG), or nanoparticles (NP) containing CG, to the extender before cooling on sperm quality in stallion semen. Ejaculates from 6 stallions were extended and split between six treatment groups (control, a-tocopherol [TOC], CG1, CG0.5, NP1 and NP0.5), stored in cryotubes at $4{ }^{\circ} \mathrm{C}$.
\end{abstract}

Results: Aliquots were analysed by computer-assisted sperm motility analysis on the day of collection, and after $24 \mathrm{~h}$ and $48 \mathrm{~h}$ of cold storage. After $48 \mathrm{~h}$, the total motility with NP1 $(78.53+6.31 \%)$ was similar to control $85.79+6.31 \%$ at $0 \mathrm{~h}$. The same pattern was observed for progressive motility. Membrane integrity assessed by flow cytometer was similar between control, TOC and G1 at all storage times. The DNA fragmentation in the control group increased at all time points, whereas chromatin integrity was maintained after $24 \mathrm{~h}$ in TOC and NP0.5 compared to $0 \mathrm{~h}$. There was no increase in the proportion of live spermatozoa producing hydrogen peroxide, but there was a tendency for an increased proportion of spermatozoa in the live superoxide category in CG1 after $24 \mathrm{~h}$ cooled storage.

Conclusions: The addition of CG or CG-derived NP to extender for stallion semen was not harmful to the sperm cells. Keywords: Cashew gum, Cooling, Nanoparticles, Semen, Stallion

\section{Background}

Cooled stallion semen is widely used for equine artificial insemination since fertility rates are higher than frozen semen [1], even when the semen is used $36 \mathrm{~h}$ after collection [2]. The plasma membrane in stallion spermatozoa has a low ratio of cholesterol to phospholipids, resulting in susceptibility to cold shock during storage at low temperatures [3]; thus cooling the semen results in better sperm survival than cryopreservation. Thermal shock due to changes in temperature may cause injuries to the sperm membrane. Other functional and structural

\footnotetext{
*Correspondence: isabel_limaverde@yahoo.com.br

${ }^{4}$ Department of Clinical Sciences, Swedish University of Agricultural Sciences, Box 7054, 75007 Uppsala, Sweden

Full list of author information is available at the end of the article
}

parameters such as motility, DNA integrity, production of reactive oxygen species (ROS) and changes in the acrosome [4] also occur, thus decreasing the survival and fertilizing ability of spermatozoa.

Different substances and compounds can be added to semen extenders to improve sperm quality. Gums are hydrocolloids that could be interesting for semen preservation; some studies have shown positive effects of different gums on cooled and cryopreserved semen. Ali et al. [5] showed the action of gum arabic on the preservation of cooled stallion semen, whereas Gastal [6] successfully demonstrated the cryoprotectant potential of xanthan gum on the membrane integrity of ovine spermatozoa. Furthermore, this gum did not affect important parameters such as membrane integrity and motility of human spermatozoa [7]. Other hydrocolloids, such as guar and 
agar, were used in the cryopreservation of human semen [7], improving sperm morphology and integrity of plasma and acrosomal membranes.

Cashew gum (CG) is extracted from the trunk of the cashew tree (Anacardium occidentale L.), widely present in northeastern Brazil. Some studies showed that CG exhibits anti-inflammatory [8], gastroprotective [9], antimicrobial [10,11] and antidiarrheal [12] properties. It has been successfully used in the food and beverage industry as a colloidal stabilizer thickening as well as a gelling agent, in a similar fashion to other hydrocolloids, being a low cost compound, odorless, tasteless and nontoxic [13]. Due to these characteristics and the previous results obtained when different hydrocolloids were added to semen extenders, we hypothesized that CG can act as protectant during the cooling process of stallion semen.

An alternative additive could be to use nanoparticles (NP) produced from CG, due to their biocompatibility and low cytotoxicity. These NP bind to the cell membrane to deliver antioxidant substances, facilitating their diffusion through the sperm membrane. However, properties such as sperm morphology, size and superficial charge must be carefully evaluated to ensure quality, safety and efficacy, if these NP are to be used in semen extenders $[14,15]$. Some studies have shown the successful use of NP to improve bovine [16], swine [17] and rooster [16] semen quality.

Thus, our aim in this study was to evaluate the effects of addition of CG, or NP containing CG, to the extender before cooling on sperm quality in stallion semen.

\section{Methods}

\section{Study design}

Semen was collected from six Warmblood stallions during the breeding season (July 2018) at a commercial stud (Lövsta Stud, Upplands Väsby, Sweden), using an artificial vagina according to standard husbandry practices. The stallions were aged between 3 and 18 years old (stallion 1-8 years old; stallion 2-14 years old; stallion 3-12 years old; stallion 4-43 years old; stallion 5-8 years old; stallion 6-18 years old), and were of known fertility. Immediately after collection, each semen sample was extended in Kenney's extender $(100 \mathrm{~mL}$ distilled water; 4.9 g glucose; 2.4 g skimmed milk) to a sperm concentration of $200 \times 10^{6}$ spermatozoa $/ \mathrm{mL}$. The extended samples were transported to the laboratory at the Swedish University of Agricultural Sciences (Uppsala, Sweden) in an insulated box at $6^{\circ} \mathrm{C}$.

At the laboratory the sperm suspensions were further diluted 1:1 (final concentration $100 \times 10^{6}$ spermatozoa $/ \mathrm{mL}$ ) in Kenney's extender containing CG, $\mathrm{NP}$ or $\alpha$-tocopherol (TOC) according to the experimental group, as follows: Control (Kenney's extender);
TOC (Kenney's extender $+\alpha$-tocopherol $2 \mathrm{mM}$ ); G1 (Kenney's extender + cashew gum $1 \mathrm{mg} / \mathrm{mL}$ ); G0.5 (Kenney's extender + cashew gum $0.5 \mathrm{mg} / \mathrm{mL}$ ); NP1 (Kenney's extender $+1 \mathrm{mg} / \mathrm{mL}$ nanoparticles containing cashew gum and $\alpha$-tocopherol); NP0.5 (Kenney's extender $+0.5 \mathrm{mg} / \mathrm{mL}$ nanoparticles containing cashew gum and $\alpha$-tocopherol). The samples were stored in cryotubes at $4{ }^{\circ} \mathrm{C}$ and analyzed on the day of collection and after 24 and $48 \mathrm{~h}$.

The nanoparticles were prepared by nanoprecipitation with $1.0 \%$ of CG and $10 \%(\mathrm{w} / \mathrm{w})$ of $\alpha$-tocopherol, based on our previous study (Loureiro et al., unpublished data). Briefly, $1 \mathrm{mg} / \mathrm{mL}$ of CG was dissolved in an aqueous solution using magnetic stirring (Kasvi, K40-1820 $\mathrm{H})$ for $30 \mathrm{~min}$ to obtain the aqueous phase. The organic phase was composed of $10 \% \alpha$-tocopherol dissolved in ethanol under magnetic stirring (Kasvi, K40-1820 H) for $30 \mathrm{~min}$. After that, the organic phase was poured into the aqueous phase maintaining magnetic stirring for $30 \mathrm{~min}$. The solvent was evaporated in a rotavapor at $35^{\circ} \mathrm{C}$, followed by the lyophilization process. The concentration of $\alpha$-tocopherol in the experimental group TOC (10\%) was chosen from previous studies [2].

\section{Sperm concentration}

The sperm concentration in all samples was evaluated using a Nucleocounter-SP 100 cell counter (Chemometec, Allerød, Denmark) [18]. Briefly, an aliquot of $50 \mu \mathrm{L}$ from each sample was mixed with $5 \mathrm{~mL}$ of reagent $\mathrm{S} 100$ in a sample cup. A cassette containing propidium iodide (PI) was filled with the mixture before inserting it into the Nucleocounter-SP100. The total cell count was displayed after $30 \mathrm{~s}$.

\section{Computer-assisted sperm analysis (CASA)}

CASA was performed using a SpermVision analyzer (Minitűb GmbH, Tiefenbach, Germany), connected to an Olympus BX 51 microscope (Olympus, Tokyo, Japan) with a heated stage $\left(38{ }^{\circ} \mathrm{C}\right)$. The microscope was fitted with a $20 \times$ objective and a $\times 10$ eyepiece; the camera operated at 60 frames per second. Aliquots of $5 \mu \mathrm{L}$ from the sperm samples were pipetted on to a warm glass slide and a coverslip was placed on top. Sperm motility was analyzed in eight fields (at least 1000 spermatozoa) using the software program (SpermVision) with settings adjusted for stallion spermatozoa. Particles with an area ranging from 20 to $100 \mu \mathrm{m}^{2}$ were included in the analysis. Sperm were considered be immotile if average path velocity $(\mathrm{VAP})<20$, and locally motile if $\mathrm{VAP}>20$ and $<30$, straightness $(\mathrm{STR})<0.5$, curvilinear velocity $(\mathrm{VCL})<9[19]$. 


\section{Flow cytometry}

Flow cytometry assays were performed according to a previous study, with minor modifications [19], using the staining protocols provided in the next sections. The flow cytometer used to evaluate the spermatozoa in all assays was a FACSVerse (BDBiosciences, San José, CA, USA).

\section{Sperm plasma membrane integrity (MI)}

The MI was evaluated using SYBR-14 and propidium iodide (PI) (LIVE/DEAD ${ }^{\circledR}$ Sperm Viability Kit L-7011; Invitrogen $^{\mathrm{TM}}$ Molecular Probes ${ }^{\mathrm{TM}}$, Eugene, Oregon, USA), according to the procedure described previously [19]. The stock solution of SYBR-14 (1 mM) was diluted 1:50 in CellWash (BD Biosciences) to prepare a fresh SYBR-14 working solution $(0.02 \mathrm{mM})$. A $300 \mu \mathrm{L}$ aliquot of $2 \times 10^{6}$ spermatozoa/mL in CellWash sperm suspension was labeled with $0.6 \mu \mathrm{L}$ SYBR-14 working solution and $3 \mu \mathrm{L} \mathrm{PI} ; 2.4 \mathrm{mM}$ ), then incubated at $37^{\circ} \mathrm{C}$ for $10 \mathrm{~min}$ in the dark. A total of 30.000 events was collected and quantified as proportions of the population. Excitation was induced by a blue laser $(488 \mathrm{~nm})$. Green fluorescence was detected with a fluorescence channel FL1 band-pass filter (527/32 nm), whereas red fluorescence was measured using a FL3 band-pass filter $(700 / 54 \mathrm{~nm})$. After gating, the spermatozoa were classified according to the degree of integrity of the plasma membrane, as membrane intact (SYBR14+-PI-), and membrane damaged (SYBR14+-PI+) or (SYBR14$\mathrm{PI}+)$. Only the proportion of membrane intact spermatozoa are reported in this study.

\section{Mitochondrial membrane potential (MMP)}

Evaluation of MMP was done by staining the spermatozoa with the lipophilic cationic mitochondrial membrane potential probe 5,5',6,6'-tetrachloro-1,1',3,3'-tetraethylbenzimidazolylcarbocyanine iodide (JC-1, Invitrogen ${ }^{\mathrm{TM}}$ Molecular Probes $^{\mathrm{TM}}$, Eugene, OR, USA), according to previous studies [20] with minor alterations. Briefly, an aliquot of $400 \mu \mathrm{L}$ sperm suspension at a final concentration of $2 \times 10^{6}$ spermatozoa/mL in CellWash was labeled with $1.2 \mu \mathrm{L}$ of $3 \mathrm{mM} \mathrm{JC}-1$ and incubated at $37^{\circ} \mathrm{C}$ for $30 \mathrm{~min}$ in the dark. Excitation of $\mathrm{JC}-1$ in stained cells was obtained by a blue laser (488 nm). Emitted fluorescence was detected using both FL1 band-pass (527/32 nm) and FL2 (586/42 nm) filters. Compensation values were $80 \%$ for FL2-FL1 and $0.5 \%$ for FL1-FL2. After gating to identify spermatozoa, 30,000 cells were evaluated and classified as having high respiratory activity MMP-H (orange fluorescence) or low respiratory activity MMP-L (green fluorescence).

\section{Reactive oxygen species (ROS)}

The staining procedure was described previously [21]. Two sets of samples were prepared for each sperm suspension: an aliquot of the sperm suspension ( 2 million spermatozoa in $300 \mu \mathrm{L}$ CellWash) was stained with $9 \mu \mathrm{L}$ of $40 \mu \mathrm{M}$ Hoechst 33258 (HO; Sigma, Stockholm, Sweden), $9 \mu \mathrm{L}$ of $40 \mu \mathrm{M}$ hydroethidine (HE; Invitrogen ${ }^{\mathrm{TM}}$ Molecular Probes ${ }^{\mathrm{TM}}$, Eugene, Oregon, USA), and $9 \mu \mathrm{L}$ of $2 \mathrm{mM} \mathrm{2}$, 7'-dichlorodihydrofluorescein diacetate (DCFDA; Invitrogen ${ }^{\mathrm{TM}}$ Molecular Probes ${ }^{\mathrm{TM}}$, Eugene, OR, USA). The samples were incubated at $38{ }^{\circ} \mathrm{C}$ for $30 \mathrm{~min}$ in the dark, then analyzed for ROS content using the flow cytometer. Excitation was performed with a blue laser $(488 \mathrm{~nm})$ and a violet laser $(405 \mathrm{~nm})$. The green fluorescence was detected with a FL1 band-pass filter $(527 / 32 \mathrm{~nm})$, red fluorescence was measured using a FL3 band-pass filter $(700 / 54 \mathrm{~nm})$, and green fluorescence excited by the violet laser was detected with a FL5 band-pass filter $(528 / 45 \mathrm{~nm})$. A total of 30,000 sperm-specific events was evaluated after gating out debris, and the spermatozoa were classified as follows: viable, superoxide-negative; viable, superoxide-positive; non-viable, superoxide-positive; viable, $\mathrm{H}_{2} \mathrm{O}_{2}$-negative; viable, $\mathrm{H}_{2} \mathrm{O}_{2}$-positive; non-viable, $\mathrm{H}_{2} \mathrm{O}_{2}$-negative; and non-viable, $\mathrm{H}_{2} \mathrm{O}_{2}$-positive.

\section{Sperm chromatin structure assay (SCSA)}

This assay was performed according to the previously described method $[18,22]$. Briefly, equal volumes of sperm suspension and Tris-sodium chloride-EDTA buffer (TNE) $(0.15 \mathrm{~mol} / \mathrm{L} \mathrm{NaCl}, 0.01 \mathrm{~mol} / \mathrm{L}$ Tris- $\mathrm{HCl}$, $1 \mathrm{mmol} / \mathrm{L}$ EDTA, pH 7.4) were mixed together, snapfrozen in liquid nitrogen $\left(\mathrm{LN}_{2}\right)$ and stored at $-80{ }^{\circ} \mathrm{C}$ until subsequent evaluation by flow cytometry. At the time of analysis, the frozen sperm suspensions were thawed on crushed ice and diluted 1:10 with TNE buffer immediately before staining. Subsequently, the spermatozoa were subjected to partial DNA denaturation by mixing $100 \mu \mathrm{L}$ of sperm suspension with $200 \mu \mathrm{L}$ of acid-detergent solution $0.17 \%$ Triton X-100 (Sigma-Aldrich, St. Louis, MO, USA); $(0.15 \mathrm{~mol} / \mathrm{L}$ $\mathrm{NaCl}$, and $0.08 \mathrm{~mol} / \mathrm{L} \mathrm{HCl} ; \mathrm{pH} 1.2)$. After $30 \mathrm{~s}$, the spermatozoa were labeled with $600 \mu \mathrm{L}$ staining solution of acridine orange (AO) (Sigma-Aldrich) $(6 \mu \mathrm{g} / \mathrm{mL}$ in $0.1 \mathrm{~mol} / \mathrm{L}$ citric acid, $0.2 \mathrm{~mol} / \mathrm{L} \mathrm{Na} \mathrm{HPO}_{4}, 1 \mathrm{mmol} / \mathrm{L}$ EDTA, $0.15 \mathrm{~mol} / \mathrm{L} \mathrm{NaCl}$; pH 6.0). Within 3-5 min, the stained samples were evaluated using the flow cytometer. For each sample, at least 10,000 events were analyzed at a speed of 200 cells/s. Forward scatter (FSC), Side scatter (SSC), FL1 (green fluorescence) and FL3 (red fluorescence) were measured after excitation with a blue laser $(488 \mathrm{~nm})$. The DNA Fragmentation Index 
(\%DFI-ratio of the proportion of cells with denatured, single-stranded DNA to total cells acquired, both with stable, double-stranded DNA, and denatured singlestranded DNA) was calculated for each sample using FCS Express version 5 (DeNovo Software, Glendale, CA, USA).

\section{Statistical analysis}

All statistical analyses were performed with $\mathrm{SAS}^{\circledR}$ software version 9.3 (SAS Institute, Books $24 \times 7$ Inc. SAS/ ETS 9.3 user's guide, SAS documentation, Cary, N.C.: SAS Institute Inc., 2011), using the MIXED procedure for linear mixed models. A repeated effect of time (hours) within animals was tested. The model used included the fixed effect of treatment ( 6 classes; control, G0.5, G1, NP0.5, NP1, TOC), the fixed effect of time (3 classes; $0 \mathrm{~h}$, $24 \mathrm{~h}, 48 \mathrm{~h}$ ), and the interaction between treatment and time. Animal was set as a random effect.

Least square means (Lsmeans, \pm standard error of the mean, sem) estimated by the models were compared using the Scheffe adjustment for multiple-post ANOVA comparisons. When appropriate, a complementary t-test based on differences between paired values was applied. A contrast option was used to investigate different individual hypothesis.

\section{Results}

The data from the CASA and Flow cytometry assays have been deposited in the Mendeley Data via the Datasets partner repository [23], with the dataset identifier https ://doi.org/10.17632/xm5s94x2cx.2.

There was a significant decrease in total motility $(\mathrm{P}<0.05)$ after $48 \mathrm{~h}$ cooling compared with the day of collection (time $0 \mathrm{~h}$ ), in the groups control, G1, G0.5 and NP0.5 (Fig. 1). However, when the semen samples were treated with NP $1 \mathrm{mg} / \mathrm{mL}$, the total motility was preserved $(\mathrm{P}>0.05)$ at all time points.

Control and TOC showed a decrease $(\mathrm{P}<0.05)$ in progressive motility (Fig. 2) after $24 \mathrm{~h}$ of storage compared to $0 \mathrm{~h}$, and G1 showed a decrease after $48 \mathrm{~h}$ compared to $24 \mathrm{~h}$. As previously noted for total motility, the group NP1 showed similar progressive motility at all storage times $(\mathrm{P}>0.05)$. Moreover, NP0.5 showed a decrease in progressive motility at $48 \mathrm{~h}$ of storage compared to $0 \mathrm{~h}$ $(\mathrm{P}<0.05)$.

A significant decrease $(\mathrm{P}<0.05)$ in $\mathrm{MI}$ was observed after $24 \mathrm{~h}$ compared to $0 \mathrm{~h}$ (Fig. 3) in groups G0.5, NP0.5 and NP1, although these levels then remained stable up to $48 \mathrm{~h}$. However, MI was similar $(\mathrm{P}>0.05)$ at all storage times in control, TOC and G1.

MMP (Fig. 4) did not change among treatments or storage times $(\mathrm{P}>0.05)$.

The control group showed increased DNA fragmentation $(\mathrm{P}<0.05)$ after $24 \mathrm{~h}$ and $48 \mathrm{~h}($ Fig. 5). The DNA fragmentation was maintained $(\mathrm{P}>0.05)$ after $24 \mathrm{~h}$ of cooled storage compared to $0 \mathrm{~h}$ in the groups TOC and

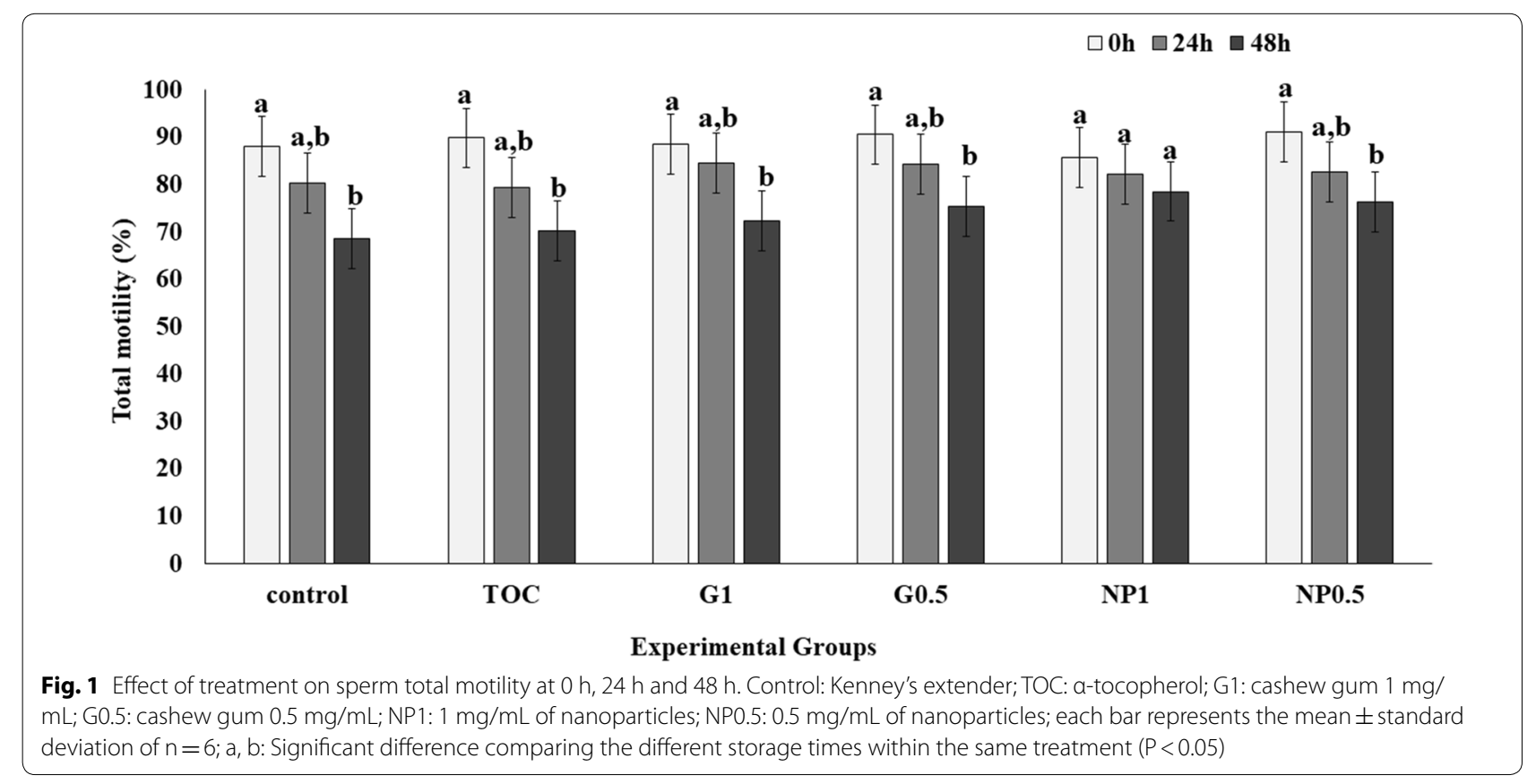




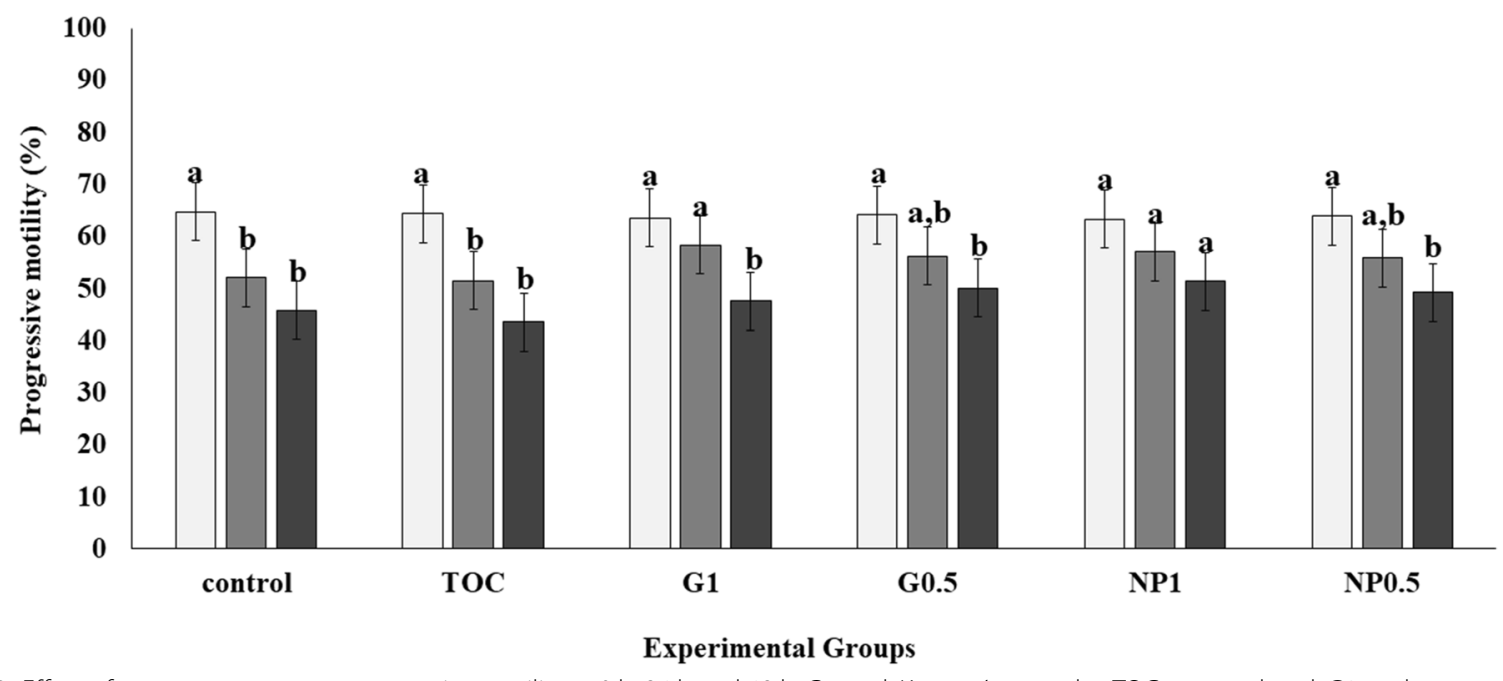

Fig. 2 Effect of treatment on sperm progressive motility at 0 h, $24 \mathrm{~h}$ and $48 \mathrm{~h}$. Control: Kenney's extender; TOC: a-tocopherol; G1: cashew gum $1 \mathrm{mg} / \mathrm{mL}$; G0.5: cashew gum $0.5 \mathrm{mg} / \mathrm{mL}$; NP1: $1 \mathrm{mg} / \mathrm{mL}$ of nanoparticles; NP0.5: 0.5 mg/mL of nanoparticles; each bar represents the mean \pm standard deviation of $n=6$; $a$, b: Significant difference comparing different storage times within the same treatment $(P<0.05)$

\section{$\square 0 \mathrm{~h} \square \mathbf{2 4 h} \square 48 \mathrm{~h}$}

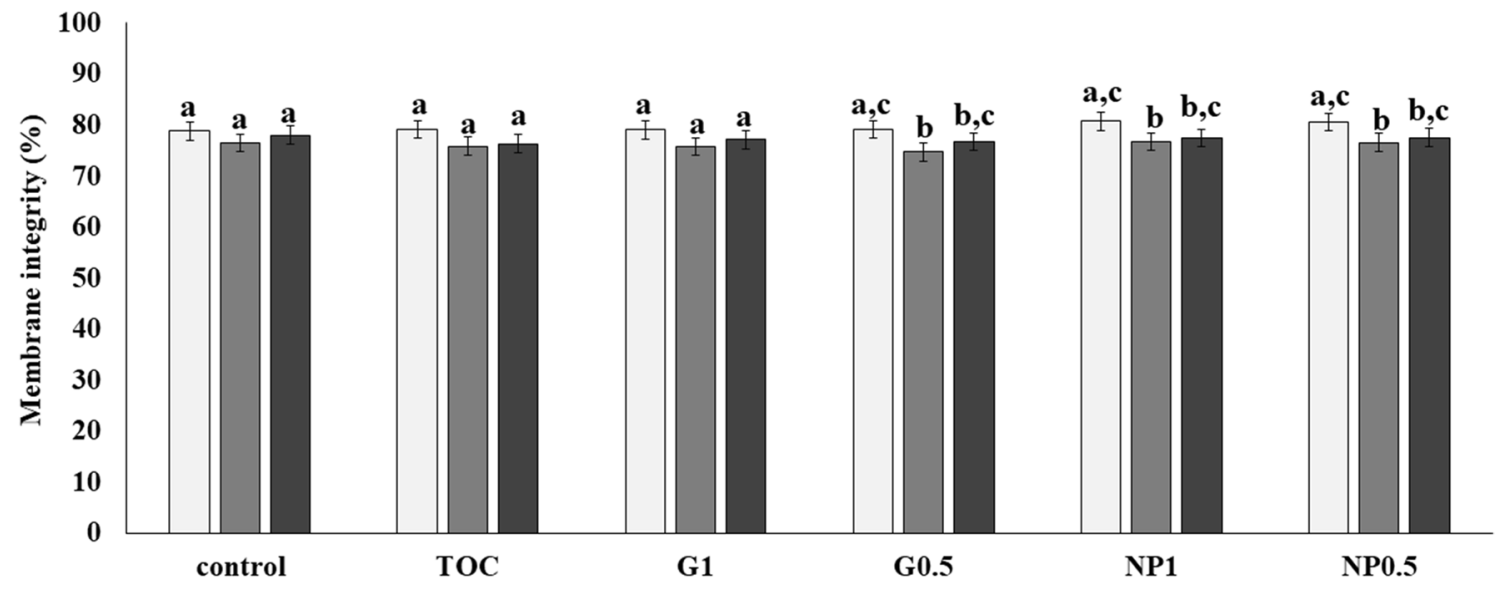

Experimental Groups

Fig. 3 Evaluation of treatment on stallion sperm plasma membrane integrity at 0 h, $24 \mathrm{~h}$ and 48 h. Control: Kenney's extender; TOC: a-tocopherol; G1: cashew gum 1 mg/mL; G0.5: cashew gum 0.5 mg/mL; NP1: 1 mg/mL of nanoparticles; NP0.5: 0.5 mg/mL of nanoparticles; each bar represents the mean \pm standard deviation of $n=6$; a-c Significant difference comparing different storage times within the same group $(P<0.05)$

NP0.5; a significant increase in \%DFI $(\mathrm{P}<0.05)$ in these same groups was observed only after $48 \mathrm{~h}$. There was increased DNA fragmentation after $24 \mathrm{~h}$ cooled storage in the groups NP1, G0.5 and G1. After 24 h cooled storage, G0.5 showed higher \%DFI than NP1, TOC and control groups $(\mathrm{P}<0.05)$.
There were no differences $(\mathrm{P}>0.05)$ in live $\mathrm{H}_{2} \mathrm{O}_{2}$ in all treatments and at all evaluation time points (Fig. 6). However, there was a tendency $(\mathrm{P}=0.06)$ to increased production of live $\mathrm{SO}^{+}$in group $\mathrm{G} 1$ after $24 \mathrm{~h}$, compared to $0 \mathrm{~h}$. 

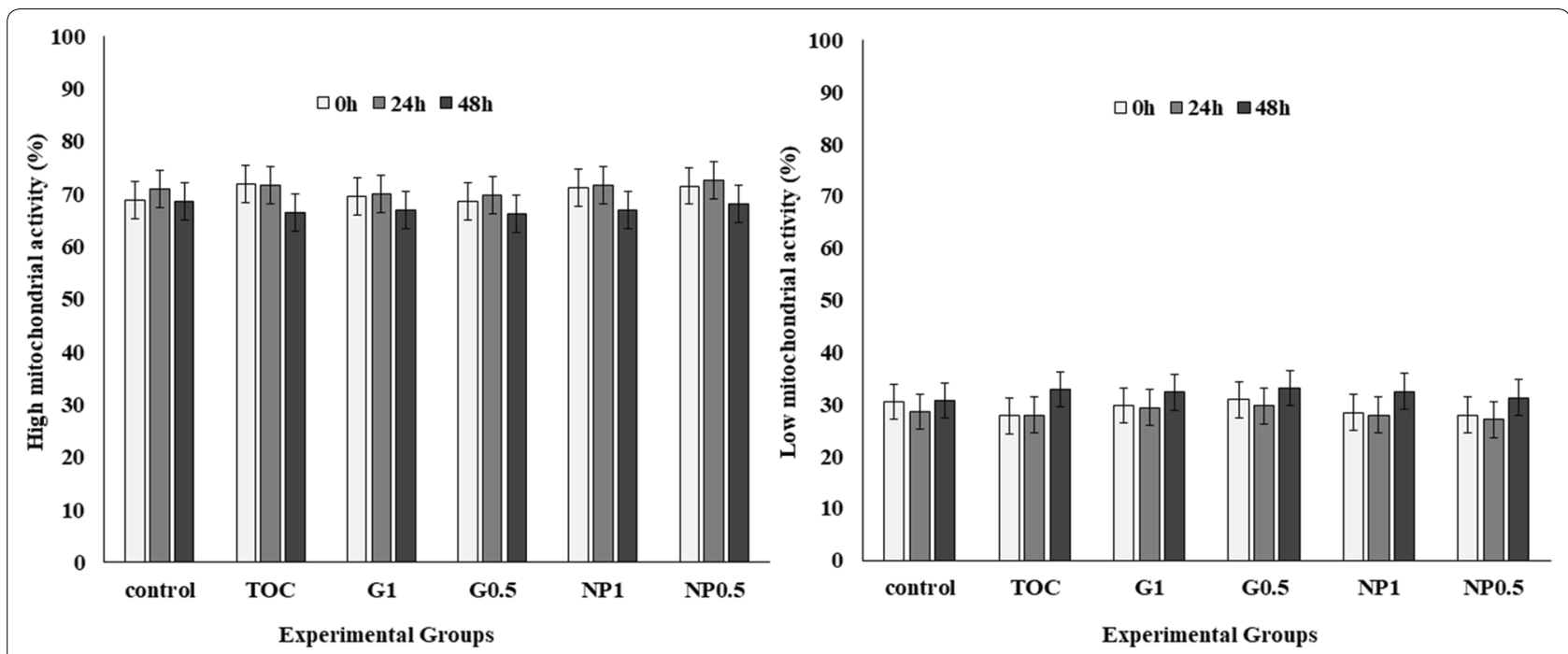

Fig. 4 Effect of treatment on high mitochondrial activity in stallion sperm at 0 h, $24 \mathrm{~h}$ and 48 h. Control: Kenney's extender; TOC: a-tocopherol; G1: cashew gum 1 mg/mL; G0.5: cashew gum 0.5 mg/mL; NP1: $1 \mathrm{mg} / \mathrm{mL}$ of nanoparticles; NP0.5: $0.5 \mathrm{mg} / \mathrm{mL}$ of nanoparticles; each bar represents the mean \pm standard deviation of $n=6$

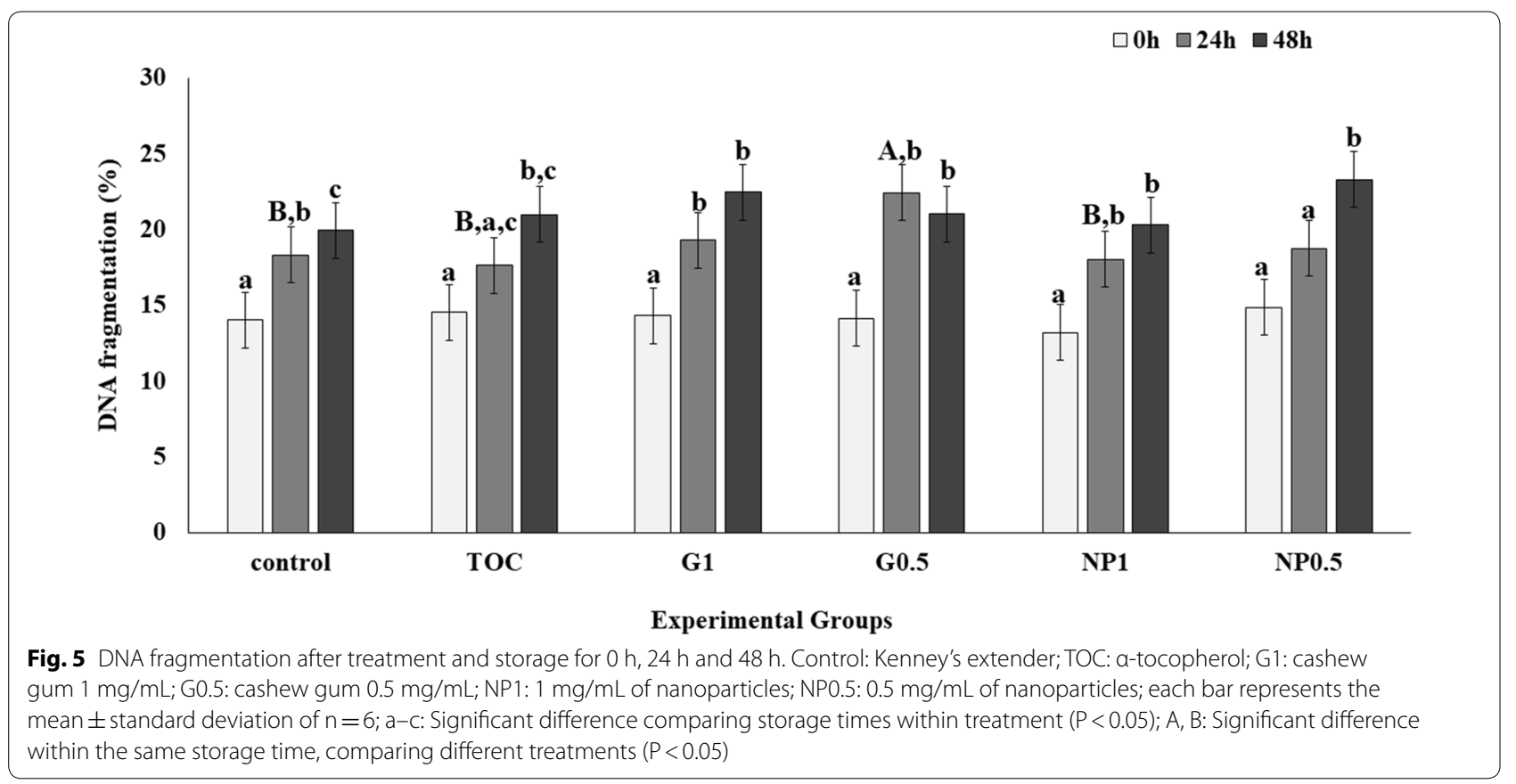

\section{Discussion}

The use of cooled semen samples is a common choice for commercial equine AI. However, this procedure still causes damage to the sperm cell during cold storage, and new alternatives are needed to improve the process. To our knowledge, this is the first study to use CG and NP derived from CG in order to improve the quality of cooled stallion semen.
In the present study, we observed that only the NP1 group was able to maintain both total and progressive motilities during the entire storage period (up to 48 h) (Figs. 1 and 2). In contrast to our findings, Pugliesi et al. [3] showed decreased sperm motility when using gum arabic in different concentrations in equine semen cooled for up to $96 \mathrm{~h}$. According to these latter authors, this result is due to the increased viscosity that usually 

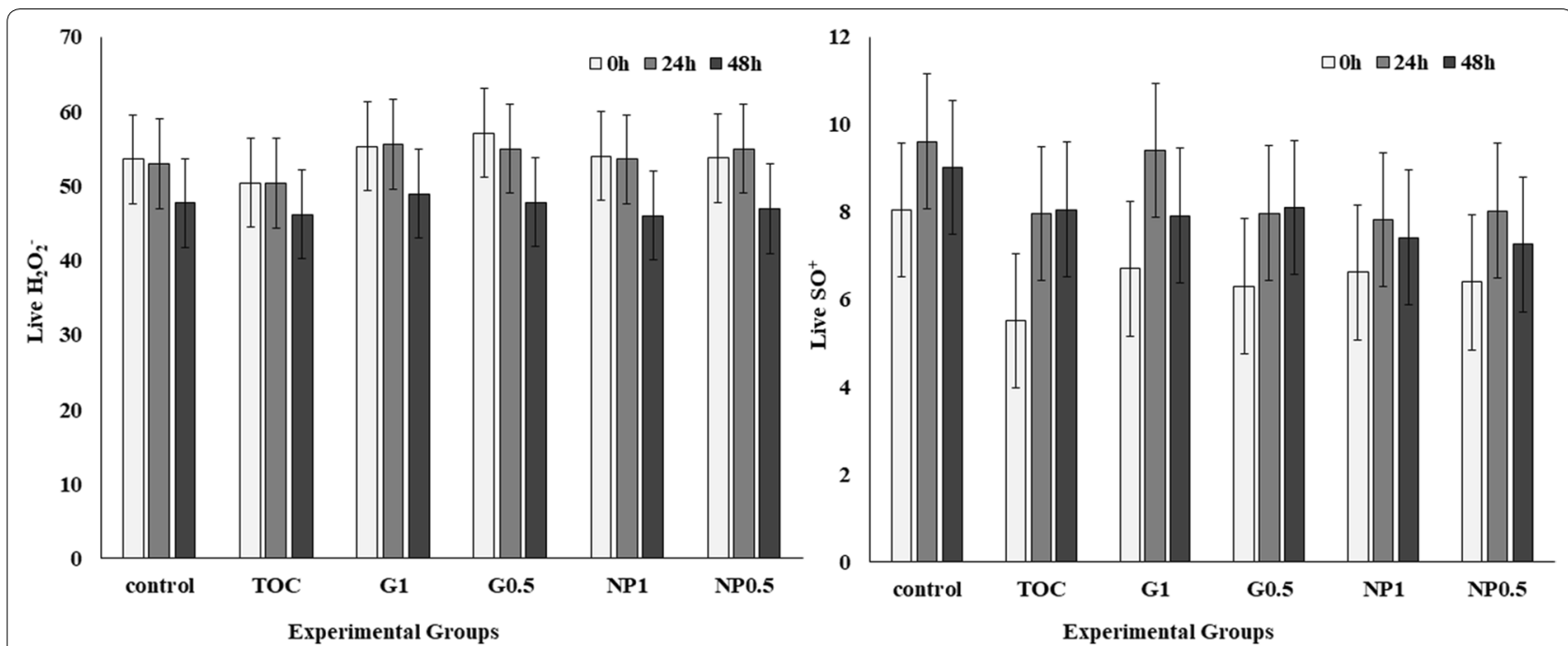

Fig. 6 Flow cytometry analysis of reactive oxygen species (ROS) generation $\left(\mathrm{H}_{2} \mathrm{O}_{2}\right.$ and $\left.\mathrm{SO}^{+}\right)$of stallion spermatozoa, at $0 \mathrm{~h}, 24 \mathrm{~h}$ and $48 \mathrm{~h}$ in different treatments. Control: Kenney's extender; TOC: a-Tocopherol; G1: Cashew gum 1 mg/mL; G0.5: Cashew gum 0.5 mg/mL; NP1: 1 mg/mL of nanoparticles; NP0.5: $0.5 \mathrm{mg} / \mathrm{mL}$ of nanoparticles; each bar represents the mean \pm standard deviation of $n=6$; $a$, b: Significant difference within the same group, comparing different storage times $(P<0.05)$

occurs when a hydrocolloid is added to an aqueous solution. In our study, no viscosity changes were observed in the tested media, which may have contributed to the different results in the two studies. In addition, the combination $\mathrm{CG}+\mathrm{NP}+\alpha$-tocopherol in Kenney's extender may have been ideal for maintaining motility throughout the cold storage period. Another factor to be considered is that in our experiment the seminal plasma was not removed from the collected samples, since the collection was performed according to standard husbandry practices in the commercial station. The benefits of removal of seminal plasma are debated since several studies reported different results in the presence or absence of seminal plasma during cooling or cryopreservation. It has also been reported that the use of extenders contributes significantly to reducing the negative effects of seminal plasma on sperm motility during cooled storage [19, 24]. Physiologically, it has been shown that sperm environment influences motion characteristics, and seminal plasma increases sperm motility and also promotes sperm activation [25].

Groups G0.5, NP0.5, NP1 showed a reduction in MI after $24 \mathrm{~h}$, but then remained stable up to $48 \mathrm{~h}$ (Fig. 3). Previous studies also report a reduction in the values of some sperm parameters, such as MI, after cooling or cryopreservation and it seems that it is not possible to avoid some negative effects of cold shock [26]. However, in control, TOC and G1, MI was maintained up to $48 \mathrm{~h}$ of cooled storage. In the present study, we used Kenney's extender, containing skimmed milk, which is important to prevent cold shock $[27,28]$. The presence of casein micelles in the skimmed milk protects against the removal of phospholipids and cholesterol from the sperm plasma membrane during the cooling procedure [3].

Previous studies have shown that the addition of the antioxidant $\alpha$-tocopherol to semen extender may improve cryopreservation or cooling of stallion semen [2, 29]; this antioxidant avoids the peroxidation of lipids in the plasma membrane, thus contributing to sperm preservation [30]. Gums provide protection against cold shock because of their physicochemical characteristics since they can retard or minimize the following processes: crystallization of water or sugar; gravitational sedimentation of suspended particles; loss of small molecules or ions due to the formation of an impermeable film; and syneresis in the gels, i.e. loss of water from the system [31-33]. In addition, these substances can bind to plasma membrane lipids, preventing efflux from the cells and contributing to the maintenance of cellular integrity [34].

Nanoparticles, due to their small size, may be easily integrated into the cells and migrate into different intracellular compartments. Moreover, NP show high stability, which enables them to be used over a long distance, thereby improving the delivery of some substances [35]. In addition, CG in controlled drug delivery systems, via NP, showed positive and successful results within different applications, such as antimicrobial activity [36, 37].

When mitochondrial activity was analyzed, all the treatments presented similar results at all storage times (Fig. 4). Such evaluation is a valuable test of sperm 
quality, since reduced mitochondrial activity is directly associated with sperm abnormalities [38, 39]. Our data suggest that GC and NP did not present toxic effects to sperm cells, considering that all the experimental groups were similar to the control, where only Kenney's was used as extender.

The \%DFI in the control group was increased when all the cooling periods were compared. The groups TOC and NP0.5 maintained DFI up to $24 \mathrm{~h}$ when compared to $0 \mathrm{~h}$, but showed an increase at $48 \mathrm{~h}$. However, NP1, G0.5 and G1 groups showed increased \%DFI after $24 \mathrm{~h}$ but levels were then maintained up to $48 \mathrm{~h}$ (Fig. 5). The \%DFI can be used to assess sperm DNA damage and can be directly associated with fertility $[26,40]$.

Some ROS such as $\mathrm{H}_{2} \mathrm{O}_{2}$ can increase sperm oxidative stress, which can cause cell damage, impairment of sperm fertility, and pathological conditions [26, 41, 42]. The storage of cooled stallion semen for long periods can induce sperm apoptosis due to oxidative stress and Johannisson et al. [21] showed that ROS can be a determinant factor of fertility reduction in stallions. However, our results showed similar live $\mathrm{H}_{2} \mathrm{O}_{2}$ levels in all treatments, suggesting that neither the extender, nor the gum, the nanoparticles or the tocopherol were harmful to spermatozoa by the production of this category of ROS (Fig. 6). It is already known that CG has a non-toxic heteropolysaccharide complex [11], which may have contributed to this result. Furthermore, there was a tendency for an increased proportion of spermatozoa in the live $\mathrm{SO}^{+}$category in $\mathrm{G} 1$ after $24 \mathrm{~h}$ cooling, suggesting more metabolically active cells in this group [21].

\section{Conclusions}

Our results suggest that CG and its NP can be used for cryopreservation of stallion semen and did not present harmful effects to sperm cells, at least in the concentrations used in this study. However, further investigations are necessary to verify the effects of other concentrations of CG and NP, sperm fertilizing ability, freezability and toxicity of the tested compounds.

\begin{abstract}
Abbreviations
CASA: Computer-assisted sperm analysis; CG: Cashew gum; CG1: Kenney's extender + cashew gum $1 \mathrm{mg} / \mathrm{mL}$; CG0.5: Kenney's extender + cashew gum $0.5 \mathrm{mg} / \mathrm{mL}$; \%DFl: DNA fragmentation index; MI: Membrane integrity; MMP: Mitochondrial membrane potential; NP: Nanoparticles; NP1: Kenney's extender $+1 \mathrm{mg} / \mathrm{mL}$ nanoparticles containing cashew gum and a-tocopherol; NP0.5: Kenney's extender $+0.5 \mathrm{mg} / \mathrm{mL}$ nanoparticles containing cashew gum and a-tocopherol; PI: Propidium iodide; STR: Straightness; TNE: Tris-sodium chloride-EDTA buffer; TOC: a-Tocopherol; VAP: Average path velocity; VCL: Curvilinear velocity.
\end{abstract}

\section{Acknowledgements}

We are grateful to the staff in the stud at Lövsta Stud Station (Upplands Väsby, Sweden), for providing the semen samples and the Cells for Life Platform at
SLU for providing the facilities for this project. The infrastructure for the Cells for Life platform was partly funded by the Infrastructure Committee, SLU, Sweden. The Institute of Macromolecular Chemistry and the researchers there contributed to the first step of this study.

\section{Prior publication}

Data have not been published previously.

\section{Authors' contributions}

$\mathrm{KCL}$ developed the nanoparticles under the supervision of AJa and PS. KCL conducted part of the analysis under supervision from IBLV. JMM provided the laboratory space and coordinated the provision of semen samples from the stud. AJo conducted the flow cytometry analysis. TN performed the statistical analysis. $\mathrm{KCL}$ conducted the analysis interpretation under supervision from IBLV and JMM. IBLV and JMM coordinated the writing process. PS and MCM contributed to the writing process. KCL and IBLV were major contributors to the manuscript, with substantial contributions from the other authors. All authors participated in the discussions and revisions of the entire text. All authors read and approved the final manuscript.

\section{Funding}

Open access funding provided by Swedish University of Agricultural Sciences. This study was funded by the Swedish University of Agricultural Sciences (SLU-Linnea och Axel Ericssons Stipendiefond) awarded to Isabel B. Lima-Verde, and the Swedish Norwegian Foundation for Equine Research, Stockholm H-14-47-008, awarded to JM Morrell. Kahynna C. Loureiro received grants from Coordination for the Improvement of Higher Education Personnel (CAPES, Brazil) and Czech Academy of Sciences, UNESCO and IUPAC (Czech Republic).

\section{Availability of data and materials}

The original dataset generated during the current study are available in the Mendeley Data repository, https://doi.org/10.17632/xm5s94x2cx.2.

\section{Ethics approval and consent to participate}

Collection of semen from stallions using an artificial vagina is regarded as a standard husbandry practice in Sweden and does not require permission from an ethical committee or from the Board of Agriculture.

\section{Consent for publication}

Not applicable.

\section{Competing interests}

The authors declare that they have no competing interests.

\section{Author details}

${ }^{1}$ Laboratory of Nanotechnology and Nanomedicine (LNMED), Institute of Technology and Research (ITP), Av. Murilo Dantas 300, Aracaju 49010-390, Brazil. ${ }^{2}$ Postgraduate Program in Industrial Biotechnology (PBI), Tiradentes University (UNIT), Av. Murilo Dantas 300, Aracaju 49032-490, Brazil. ${ }^{3}$ Department of Supramolecular Polymer Systems, Institute of Macromolecular Chemistry, Heyrovského námestí 2, 16206 Prague 6, Czech Republic. ${ }^{4}$ Department of Clinical Sciences, Swedish University of Agricultural Sciences, Box 7054, 75007 Uppsala, Sweden.

Received: 5 March 2020 Accepted: 12 June 2020

Published online: 18 June 2020

\section{References}

1. Aurich J, Aurich C. Developments in European horse breeding and consequences for veterinarians in equine reproduction. Reprod Domest Anim. 2006:41:275-9.

2. Nogueira B, Sampaio B, Souza M, Costa e Silva E, Zúccari C. Coenzyme Q10 and a-tocopherol prevent the lipid peroxidation of cooled equine semen. Reprod Domest Anim. 2015;50:1003-10.

3. Pugliesi G, de Carvalho GR, Rates DM, Ker PG, da Matta MP, de Oliveira $R R$, et al. Viability and fertility of cooled equine semen diluted with skimmed milk or glycine egg yolk-based extenders. Rev Bras Zootec. 2012;41:2411-7. 
4. Yeste M, Estrada E, Rocha LG, Marin H, Rodriguez-Gil JE, Miro J. Cryotolerance of stallion spermatozoa is related to ROS production and mitochondrial membrane potential rather than to the integrity of sperm nucleus. Andrology. 2015;3:395-407.

5. Ali M, Musa MM, Alfadul S, Al-Sobayel K. Effect of gum Arabic on stallion sperm survival during cold storage and post freezing. Maced Vet Rev. 2018;41:21-31.

6. Gastal GDA. Xantana como aditivo crioprotetor externo para congelamento de sêmen ovino. Federal de Pelotas. 2012

7. Costa SMRJ, Valverde FG, Souza-Neto CM, Silveira GHC, Silveira EC, Padilha FF, et al. Processo de diluição contendo hidrocolóides para criopreservação de células somáticas e produto obtido. 2017.

8. Schirato GV, Monteiro FMF, Silva FdO, Lima Filho JL, Leão AMdAC, Porto ALF. O polissacarídeo do Anacardium occidentale L. na fase inflamatória do processo cicatricial de lesões cutâneas. Ciência Rural. 2006;36:149-54.

9. Carvalho NS, Silva MM, Silva RO, Nicolau LAD, Sousa FBM, Damasceno SRB, et al. Gastroprotective properties of cashew gum, a complex heteropolysaccharide of Anacardium occidentale, in naproxen-induced gastrointestinal damage in rats. Drug Dev Res. 2015;76:143-51.

10. Campos DA, Ribeiro AC, Costa EM, Fernandes JC, Tavaria FK, Araruna FB, et al. Study of antimicrobial activity and atomic force microscopy imaging of the action mechanism of cashew tree gum. Carbohydr Polym. 2012;90:270-4.

11. Quelemes PV, Araruna FB, de Faria BEF, Kuckelhaus SAS, da Silva DA, Mendonca RZ, et al. Development and antibacterial activity of cashew gum-based silver nanoparticles. Int J Mol Sci. 2013;14:4969-81.

12. Araujo TSL, Costa DS, Sousa NA, Souza LKM, de Araujo S, Oliveira AP, et al. Antidiarrheal activity of cashew GUM, a complex heteropolysaccharide extracted from exudate of Anacardium occidentale L. in rodents. J Ethnopharmacol. 2015;174:299-307.

13. Ali BH, Al-Husseni I, Beegam S, Al-Shukaili A, Nemmar A, Schierling S, et al. Effect of gum arabic on oxidative stress and inflammation in adenineinduced chronic renal failure in rats. PLoS ONE. 2013;8:e55242.

14. Farini VL, Camaño CV, Ybarra G, Viale DL, Vichera G, Yakisich JS, et al. Improvement of bovine semen quality by removal of membranedamaged sperm cells with DNA aptamers and magnetic nanoparticles. J Biotechnol. 2016;229:33-41.

15. Red XII-H R, Acosta-Torres LS, Serrano-Díaz P, Avilés-López YS, ToscanoTorres IA, Olivo-Zepeda IB, et al. Actas iberoamericanas de conservación animal. Actas Iberoam. Conserv Anim. Red CONBIAND; 2017.

16. Safa S, Moghaddam G, Jozani RJ, Daghigh Kia H, Janmohammadi H. Effect of vitamin $E$ and selenium nanoparticles on post-thaw variables and oxidative status of rooster semen. Anim Reprod Sci. 2016;174:100-6. https://doi.org/10.1016/j.anireprosci.2016.09.011 (Epub 2016/09/24).

17. Red X-HR, Acosta-Torres LS, Serrano-Díaz P, Avilés-López YS, ToscanoTorres IA, Olivo-Zepeda IB ea. Actas iberoamericanas de conservación animal. Actas Iberoamericanas de Conservación Animal. 2017;10(Red (ONBIAND):34-40.

18. Morrell JM, Johannisson A, Dalin A-M, Rodriguez-Martinez H. Singlelayer centrifugation with Androcoll-E can be scaled up to allow large volumes of stallion ejaculate to be processed easily. Theriogenology. 2009;72:879-84.

19. Al-Essawe EM, Johannisson A, Wulf M, Aurich C, Morrell JM. Addition of seminal plasma to thawed stallion spermatozoa did not repair cryoinjuries. Anim Reprod Sci. 2018;196:48-58.

20. Cossarizza A, Baccaranicontri M, Kalashnikova G, Franceschi C. A new method for the cytofluorometric analysis of mitochondrial membrane potential using the J-aggregate forming lipophilic cation $5,5^{\prime}, 6,6^{\prime}$-tetrachloro-1, 1',3,3'-tetraethylbenzimidazolcarbocyanine lodide (JC-1). Biochem Biophys Res Commun. 1993;197:40-5.

21. Johannisson A, Lundgren A, Humblot P, Morrell JM. Naturally and stimulated levels of reactive oxygen species in cooled stallion semen destined for artificial insemination. Animal. 2014;8:1706-14.

22. Evenson DP, Larson KL, Jost LK. Sperm chromatin structure assay: its clinical use for detecting sperm DNA fragmentation in male infertility and comparisons with other techniques. J Androl. 2002:23:25-43.

23. Loureiro KC, Lima-Verde I, Johannisson A, Ntallaris T, Jager A, Štěpánek $P$, et al. Cashew gum nanoparticles effects on cooled stallion semen. 2020 https://data.mendeley.com/datasets/xm5s94×2cx/2.
24. Love CC, Brinsko SP, Rigby SL, Thompson JA, Blanchard TL, Varner DD. Relationship of seminal plasma level and extender type to sperm motility and DNA integrity. Theriogenology. 2005;63:1584-91.

25. Heise A, Thompson PN, Gerber D. Influence of seminal plasma on fresh and post-thaw parameters of stallion epididymal spermatozoa. Anim Reprod Sci. 2011;123:192-201

26. Lima-Verde I, Johannisson A, Ntallaris T, Al-Essawe E, Al-Kass Z, Nongbua $T$, et al. Effect of freezing bull semen in two non-egg yolk extenders on post-thaw sperm quality. Reprod Domest Anim. 2018;53:127-36.

27. Ferrante AA, Neild DM, Arraztoa CC, Castex CB, Bruno S, Plaza J, et al. Comparison of whole and centrifuged egg-yolk added to Kenney's and lactose-EDTA extenders for donkey semen cryopreservation. J Equine Vet Sci. 2018;66:76-7.

28. Izadpanah G, Zare-Shahneh A, Zhandi M, Yousefian I, Emamverdi M. Melatonin has a beneficial effect on stallion sperm quality in cool condition. J Equine Vet Sci. 2015:35:555-9.

29. Yousefian I, Zare-Shahneh A, Zhandi M. The effect of coenzyme Q10 and a-tocopherol in skim milk-based extender for preservation of caspian stallion semen in cool condition. J Equine Vet Sci. 2014;34:949-54.

30. de Vasconcelos Franco JS, Faheem M, Chaveiro A, Moreira da Silva F. Effects of a-tocopherol and freezing rates on the quality and heterologous in vitro fertilization capacity of stallion sperm after cryopreservation. Theriogenology. 2016;86:957-62.

31. Mudgil D, Barak S, Khatkar BS. Guar gum: processing, properties and food applications - a review. J Food Sci Technol. 2014;51:409-18.

32. Saha A, Tyagi S, Gupta RK, Tyagi YK. Natural gums of plant origin as edible coatings for food industry applications. Crit Rev Biotechnol. 2017;37:959-73.

33. Park EY, Yoo JH, Lim S-T. Effect of aqueous impregnation of rice Kernels with gum arabic and xanthan on storage stability of frozen rice cakes. Cereal Chem J. 2017;94:640-2.

34. Prajapati VD, Jani GK, Moradiya NG, Randeria NP. Pharmaceutical applications of various natural gums, mucilages and their modified forms. Carbohydr Polym. 2013;92:1685-99.

35. Doroftei B, Simionescu G, Neculai-Valeanu S. Application of nanotechnology in the improvement of semen quality - future trend in assisted reproduction. Res Gate. 2015:6.

36. de Oliveira EF, Paula HCB, de Paula RCM. Alginate/cashew gum nanoparticles for essential oil encapsulation. Colloids Surf B Biointerfaces. 2014;113:146-51.

37. Oliveira ACJ, de Araújo AR, Quelemes PV, Nadvorny D, Soares-Sobrinho JL, Leite JRSA, et al. Solvent-free production of phthalated cashew gum for green synthesis of antimicrobial silver nanoparticles. Carbohydr Polym. 2019;213:176-83

38. Barroso G, Taylor S, Morshedi M, Manzur F, Gaviño F, Oehninger S. Mitochondrial membrane potential integrity and plasma membrane translocation of phosphatidylserine as early apoptotic markers: a comparison of two different sperm subpopulations. Fertil Steril. Elsevier. 2006;85:149-54

39. Gallon F, Marchetti C, Jouy N, Marchetti P. The functionality of mitochondria differentiates human spermatozoa with high and low fertilizing capability. Fertil Steril. 2006;86:1526-30.

40. Yang $H$, Li G, Jin $H$, Guo $Y$, Sun $Y$. The effect of sperm DNA fragmentation index on assisted reproductive technology outcomes and its relationship with semen parameters and lifestyle. Transl Androl Urol. 2019;8:356-65.

41. Aitken RJ, Baker MA. Oxidative stress, sperm survival and fertility control. Mol Cell Endocrinol. Elsevier. 2006;250:66-9.

42. Kothari S, Thompson A, Agarwal A, du Plessis SS. Free radicals: their beneficial and detrimental effects on sperm function. Indian J Exp Biol. 2010;48:425-35.

\section{Publisher's Note}

Springer Nature remains neutral with regard to jurisdictional claims in published maps and institutional affiliations. 